\title{
Poder Monetário Estrutural: do padrão ouro ao dólar flexível *
}

\author{
Ernani Teixeira Torres Filho**
}

\section{Resumo}

As necessidades de financiamento das guerras no século XVII levaram a Inglaterra a realizar inovações financeiras importantes, que deram lugar à Revolução Financeira. Esse conjunto de mecanismos - dívida pública de longo prazo, banco central e mercados secundários relevantes - permitiram à Grã-Bretanha desempenhar um papel central no sistema financeiro internacional até a $1^{\text {a }}$ Grande Guerra. Entretanto, esse ganho não proporcionou aos ingleses um poder monetário estrutural, apesar do papel central que seu mercado financeiro e sua moeda tiveram durante o padrão ouro. Diferentemente, os Estados Unidos usaram seu poder monetário estrutural tanto para implantar o regime de taxas fixas de Bretton Woods quanto para rompê-lo e substituí-lo pelo atual sistema monetário e financeiro internacional, baseado do dólar flexível. A crise de 2008 mostra que o poder estrutural americano está intacto e sem competidores potenciais relevantes.

Palavras-chave: Sistema Monetário Internacional; Poder Monetário Estrutural; Padrão ouro; Dólar fixo; Dólar flexível.

\section{Abstract \\ Structural Monetary Power: from the gold standard to the flexible dollar regime}

The need to finance wars led England to introduce important financial innovations in the late seventeenth century that gave rise to the Financial Revolution. This set of mechanisms - long-term public debt, central bank and deep secondary markets - provided Britain with a dominant position in the international monetary system until World War I. However, this gain did not provide the British with structural monetary power despite the central role their financial market and their currency held during the gold standard. In contrast, the United States used its structural monetary power not only to implement the Bretton Woods fixed-rate regime but also to break and replace it with the current flexible international dollar-based monetary and financial system. The crisis of 2008 shows that American structural power is intact and faces no relevant potential competitors.

Keywords: International Monetary System; Structural Monetary Power; Gold standard; Fixed exchange rate dollar regime; Flexible exchange rate dollar regime.

JEL F02, F30, G15, H56.

\section{Introdução}

A literatura de relações internacionais e, em particular, da Economia Política Internacional (EPI) possui contribuições importantes ao estudo das relações entre moeda, mercados financeiros e poder. Entre essas, está o conceito de poder monetário estrutural (PME) desenvolvido por Benjamin Cohen e Susan Strange. Para esses dois autores, trata-se de uma

\footnotetext{
* Artigo recebido em 23 de fevereiro de 2018 e aprovado em 24 de junho de 2018.

** Professor do Programa de Pós-Graduação em Economia Política Internacional (PEPI) do Instituto de Economia da Universidade Federal do Rio de Janeiro (UFRJ), Rio de Janeiro, RJ, Brasil. E-mail: ernanit@ hotmail.com. ORCID:

https://orcid.org/0000-0001-9588-5769.
} 
das dimensões do poder estrutural que a potência hegemônica exerce sobre as demais nações relevantes na arena internacional. Refere-se especificamente a sua capacidade de reescrever, em seu benefício, as regras que comandam, a nível global, a geração de crédito dos sistemas financeiros nacionais e a conversibilidade das diferentes moedas.

Ademais dessa perspectiva teórica, o poder monetário estrutural também guarda uma dimensão histórica. Desse ponto de vista, a origem do PME está relacionada ao comando de um país sobre um conjunto de instituições que foram fruto da Revolução Financeira ocorrida na Inglaterra no século XVIII (Roseveare, 1991). Essas inovações se materializaram na modernização da dívida pública - a introdução do "Dutch finance" (Carlos et al., 2005), na criação do banco central (Martin, 2014), e no desenvolvimento e na proteção dos mercados secundários de ativos financeiros. Esse complexo integrado de mecanismos institucionais determinaram as características básicas dos sistemas de moeda e de crédito nacionais que se constituíram nas décadas seguintes e que se mantém, com alguns ajustes, até os dias atuais. A integração desses sistemas nacionais ao dominante permite a operação global do sistema capitalista desde então.

Essa "máquina" moderna de moeda e crédito teve uma característica internacional desde o início. A originalidade e a efetividade desse novo sistema possibilitaram aos ingleses aumentar o volume de recursos à sua disposição - e de seus aliados - muito além da capacidade de seus inimigos. Consequentemente, a Inglaterra acumulou uma grande vantagem nos conflitos militares que se sucederam nos séculos XVIII e XIX. Passou a ter condições muito melhores que seus rivais para levantar recursos para financiar suas guerras (Whitley, 2013). Ao mesmo tempo, essas mesmas inovações criaram as bases para que Londres se firmasse como principal centro financeiro global enquanto a libra assumia o papel de moeda internacional dominante.

Entretanto, a hipótese sustentada nesse artigo é a de que, a despeito da centralidade alcançada pelo sistema monetário e financeiro inglês entre 1870 e 1914, a Inglaterra não chegou a deter um poder monetário estrutural frente a seus principais rivais. A montagem do sistema monetário e financeiro global do século XIX não foi fruto de regras e normas impostas pelos ingleses. A adesão de cada uma das grandes potências da época foi decorrência das vantagens que cada um desses países viu em participar do sistema monetário baseado no monometalismo britânico.

Quando esse sistema, baseado no padrão ouro, não pode mais ser gerido pelos ingleses, a Grã-Bretanha não teve poder para impor às demais potências um novo sistema monetário internacional que lhe fosse favorável. Pelo contrário, só lhe restou a opção de submeter os países que estavam sob seu domínio político direto - o Império - ou econômico - como a Argentina - para formar um bloco isolado, que manteve a libra inconversível como sua moeda internacional comum.

Essa experiência inglesa contrasta com a da supremacia monetária americana a partir do final da $2^{\text {a }}$ Guerra Mundial. A centralidade dos Estados Unidos e da sua moeda no sistema 
Poder Monetário Estrutural: do padrão ouro ao dólar flexível

monetário e financeiro internacional foi, desde a partida, fundada no poder monetário estrutural americano. A dupla vitória americana, sobre os inimigos do Eixo e sobre as pretensões do império inglês, conferiu aos EUA uma posição singular e sustentável que lhes permitiu configurar, em seu benefício, os vários contornos que o sistema monetário internacional viria a ter nas décadas seguintes.

Diante desse cenário, este texto está divido em três seções, além dessa introdução e da conclusão. A primeira aborda de modo sucinto as questões da hierarquia das moedas e do poder monetário estrutural do ponto de vista teórico e conceitual, em particular, as contribuições de Benjamim Cohen e Susan Strange. A segunda seção analisa do ponto de vista histórico o papel que a Inglaterra e a libra esterlina tiveram na montagem do padrão ouro. O Banco da Inglaterra (BoE) tinha uma função sistêmica relevante e isso gerava vantagens para os bancos e para o governo inglês. Entretanto, a liderança britânica tinha que obedecer a limites claros, entre os quais, o mais importante era a conversibilidade da sua moeda em ouro. Isso se tornou um elemento de grande fragilidade para a Inglaterra a partir de 1914.

A terceira seção aborda os sistemas monetários que surgiram no século $\mathrm{XX}$, ambos centrados no dólar americano. Sua gestação e operação se apoiaram numa base de poder diferente do antigo regime ouro-libra já que a liderança americana se baseia em uma grande assimetria de poder frente a seus rivais. Seguem-se as conclusões.

\section{Hierarquia de moedas e Poder Monetário Estrutural}

O dólar se sustenta no topo da hierarquia monetária internacional desde 1945. É, de longe, a moeda mais utilizada em todo o mundo. Segundo o Swift (2015), a moeda americana era responsável por $52 \%$ do volume total de liquidações desse sistema de transações internacionais em 2014. O mercado financeiro dos EUA é o mais líquido e profundo de todo o mundo. A maior parte das reservas internacionais - 64\% - é denominada em dólar (FMI, 2017). Todos esses indicadores apontam para uma indiscutível supremacia do dólar no conjunto das moedas utilizadas globalmente.

De acordo com a visão funcionalista, uma moeda nacional se torna internacional na medida em que passa a desempenhar no exterior as funções clássicas da moeda, como unidade de conta, reserva de valor e meio de troca, tanto para agentes públicos quanto privados (Conti et al., 2013). Essa segregação é importante por que instituições públicas e empresas têm demandas diferentes nas suas transações internacionais. Desse ponto de vista, as funções da moeda são, do ponto de vista privado: as de meio de pagamento/moeda veicular; moeda de denominação; e moeda de investimento e financiamento. Bancos centrais e tesouros nacionais, por sua vez, precisam, além disso, escolher uma das moedas internacionais como referência para sua taxa de câmbio, para suas operações de intervenção no mercado e para a denominação de suas reservas internacionais.

Ainda que muitas moedas possam ser consideradas internacionais, existe uma hierarquia entre elas. Apenas umas poucas - entre as quais se destacam o dólar, o euro, a libra 
e o iene - podem ser consideradas "plenas", pelo fato de atenderem a todas as funções. As demais são consideradas "parciais", pelo fato de desempenharem apenas algumas funções (Chey, 2013; Cohen, 2011).

Se a perspectiva funcionalista permite identificar uma clara hierarquia entre as moedas internacionais, deixa, no entanto, de lado questões políticas relevantes, que envolvem o relacionamento político entre os países emissores das moedas internacionais e os que as utilizam. As moedas internacionais não são hierarquizadas apenas porque atendem em melhores condições às necessidades de seus usuários e de seus supridores. Elas oferecem esses "serviços" desde o século XIX, como parte de um sistema global ordenado segundo regras e convenções estabelecidas ex-ante e aceitas por todos.

Como tal, essas normas estão sujeitas a mudanças, às vezes radicais, que visam permitir a acomodação de interesses de atores de mercados e de governos, em particular os da nação emissora da moeda principal. Além disso, existem vantagens e obrigações para os países emissores conforme sua posição na hierarquia no sistema. É a existência dessa assimetria de poder e de benefícios o que dá origem às críticas de que, no atual sistema monetário internacional baseado no dólar, os Estados Unidos detêm um "privilégio exorbitante" (Eichengreen, 2011).

A temática central tratada pela visão estruturalista é, portanto, a questão do poder associado à moeda internacional. Segundo Cohen, há que se fazer uma distinção entre a dimensão de processo e a de estrutura. A primeira tem um foco operacional e de curto prazo. Está associada à capacidade de se conseguir atingir um resultado desejado dentro um determinado esquema institucional de negociação entre países. A segunda dimensão, a estrutural, tem uma perspectiva temporal mais longa e está relacionada à capacidade de um país reescrever, em seu benefício, as regras do jogo da interação entre as nações (Cohen, 1977).

A definição de poder estrutural de Cohen se aproxima da que é utilizada por Susan Strange. Segundo essa autora, "structural power decides outcomes (both positive and negative) much more than relational power does" (Strange,1987, p. 553), e "structural power is the power to choose and to shape the structures of the global political economy within which other states, their political institutions, their economic enterprises, and (not least) their professional people have to operate" (Strange, 1987, p. 565).

Nesse contexto, o poder monetário é visto como uma das dimensões do poder estrutural. Ele se refere especificamente à capacidade de um país mudar, em seu próprio benefício, os mecanismos de natureza sistêmica que regem a originação de crédito e comandam a conversibilidade entre as diferentes moedas relevantes. Essas normas determinam a possibilidade de as nações emissoras de moeda internacional utilizarem seus sistemas monetário e financeiro para impedir ou postergar ajustes em suas contas externas. Consequentemente, têm repercussões sobre o grau de autonomia desses Estados na formulação de suas políticas. 
Isso pode afetar aspectos econômicos como a determinação dos níveis de emprego e de renda domésticos. Entretanto, pode também limitar a capacidade de governos sustentarem ações de poder na arena internacional, sejam de natureza econômica ou militar. Um exemplo desse segundo tipo de limitação é encontrado na crise que envolveu o Canal de Suez em 1956. A Inglaterra se viu obrigada a retirar suas forças militares da região, então recém-ocupada, como resposta à ameaça dos Estados Unidos de, em caso contrário, desestabilizarem a moeda inglesa nos mercados de câmbio e, consequentemente, a economia doméstica inglesa (KIRSHNER, 1995). Desse ponto de vista, hegemonia monetária refere-se a um sistema político e econômico "organized around a single country with acknowledged responsibilities (and privileges) as leader" na esfera monetária (Cohen, 1977, p. 9).

\section{A supremacia monetária britânica durante o padrão ouro}

Foi a partir das inovações introduzidas no início do século XVIII que Londres se firmou como principal praça financeira do mundo e a moeda inglesa adquiriu centralidade no sistema internacional. Entretanto, essa posição precisou esperar quase um século após a criação do BoE para ser alcançada. Durante todo o século XVIII, Londres e Amsterdã conviveram como os dois mais importantes centros financeiros do continente. Nesse período, colaboração e competição estiveram presentes lado a lado. Os dois mercados desenvolveram uma relação simbiótica proveitosa, que durou seis décadas (1723-1783), mas foi definitivamente extinta com a derrota de Napoleão em 1815. Só então a supremacia inglesa nas finanças internacionais se consolidou.

Ao longo desse período, as duas cidades possuíam centros financeiros com características distintas (Carlos; Neal, 2011). Londres era dominante na negociação de letras de câmbio por agentes privados enquanto Amsterdã se destacava pelo sistema de pagamentos, baseado em um banco público. Na Inglaterra, as transações eram usualmente liquidadas com letras de câmbio sendo transferidas de pessoa a pessoa por sucessivos endossos. Caso o proprietário desse título precisasse de dinheiro em espécie, poderia vendê-lo no mercado secundário ou emitir novas letras em seu nome. Na Holanda, diferentemente, os negócios eram pagos por meio da transferência de depósitos junto ao Banco de Amsterdã. Londres sediava uma importante bolsa de valores, em que corretoras atuavam ativamente na compra e venda de ações. Na Holanda, os bancos de negócios (merchants banks) tinham um papel dominante.

Na prática, esses dois mercados operavam integradamente. Os bancos e os capitais holandeses, por exemplo, eram investidores relevantes em ações em Londres. Ao mesmo tempo, ações de empresas inglesas eram utilizadas como garantia para empréstimos concedidos em Amsterdã. As duas cidades proviam serviços de liquidação de pagamentos internacionais. Entretanto, rapidamente o BoE se tornou mais importante nessa atividade, uma vez que os depósitos no Banco de Amsterdã deixaram de ser conversíveis em 1700. Com a derrota de Napoleão em 1815, a Holanda perdeu definitivamente relevância financeira frente à Inglaterra. O desaparecimento de Amsterdã como competidor, no entanto, não levou Londres a assumir uma posição incontestável no cenário financeiro europeu. 
A restauração da monarquia francesa após a queda de Napoleão abriu mercado para os ingleses financiarem o pagamento das reparações de guerra da França e de outros países na Europa. As independências latino-americanas também constituíram importantes oportunidades de negócios a partir de 1820. Entretanto, o colapso dos mercados de títulos públicos estrangeiros em 1825 e 1826 levou a City a se focar no crédito ao comércio internacional e em operações nos Estados Unidos, principalmente no setor ferroviário. Durante a crise da dívida latino-americana, o apoio do Banco do França ao $\mathrm{BoE}$ foi essencial para sustentar a conversibilidade da libra em ouro. Essa cooperação foi retomada na década de 1830, em duas outras oportunidades ao longo do século XIX e novamente na crise de 1907. A Inglaterra durante todo o século XIX e início do XX manteve um nível relativamente baixo de reservas de ouro e as utilizou apenas para garantir a liquidez externa da sua própria moeda e nunca como um instrumento de estabilização de terceiros países. Apesar de o mercado privado londrino ser o mais importante, o BoE não operou como um banco de outros bancos centrais do sistema financeiro internacional durante o período do padrão ouro.

Por mais de um século, Londres ocupou a posição de principal praça do sistema financeiro internacional. Era o centro responsável pela emissão da moeda reserva mais importante, pela maior parte das liquidações internacionais e pela maioria das emissões de dívidas de governos e de empresas de outros países. Esse papel foi seguido de perto, em várias oportunidades, por outros centros financeiros do continente. Paris, particularmente durante o Segundo Império de Napoleão III (1851-1872), deteve algumas vantagens competitivas frente à Inglaterra. A França tinha uma conta corrente desfavorável com seus parceiros continentais e, ao mesmo tempo, era superavitária com os ingleses, que tinham déficit com o resto da Europa. Segundo Plessis: "That situation imposed the franc as the continental reserve and settlement currency, which meant that Paris could play an important part as a clearing centre, be the leading exchange market in Europe, and play a key part in world payments" (Plessis, 2005, p. 42).

Com a derrota francesa frente aos prussianos em 1870, Paris perdeu relevância. A suspensão da conversibilidade do franco em ouro reduziu o interesse dos negócios internacionais em liquidar suas operações na França. Sobre esse fato, Bagehot comentou em seu livro Lombard Street que: "Since the Franco-German war, we may be said to keep the European reserve also. Deposit Banking is indeed so small on the Continent, that no large reserve need be held on account of it. [...] Formerly there were two such stores in Europe, one was the Bank of France, and the other the Bank of England. But since the suspension of specie payments by the Bank of France, its use as a reservoir of specie is at an end. No one can draw a cheque on it and be sure of getting gold or silver for that cheque. Accordingly the whole liability for such international payments in cash is thrown on the Bank of England". (Bagehot, 1873, p. 25).

A perda de competitividade do mercado financeiro francês permitiu que a supremacia inglesa se consolidasse no sistema monetário e financeiro internacional até 1931. Pouco a pouco, os países relevantes adotaram o regime monometalista inglês. Em 1870, apenas 
Poder Monetário Estrutural: do padrão ouro ao dólar flexível

Inglaterra e Portugal haviam formalmente adotado o padrão ouro. No final dessa década, quase todos os países importantes já haviam aderido. A transformação começou com a Alemanha em 1871, acompanhada pelos países escandinavos e a Holanda. Os EUA desmonetizaram formalmente a prata em 1873, apesar de na prática já estarem sujeitos ao padrão ouro desde os anos 1830. Foram seguidos pela França e pela Bélgica. As potências restantes aderiram na década de 1890: Áustria-Hungria em 1892, Rússia e Japão em 1897. Adotar o padrão ouro reduzia os custos dos financiamentos internos e externos e permitia aumentar os prazos das operações financeiras. Era, de certo modo, um selo de qualidade de risco de crédito para os Estados, empresas e bancos participantes do sistema.

Em nenhum desses casos, a adoção do padrão ouro foi decorrência de imposição ou de coerção por parte da Inglaterra. Essas decisões em todos os casos dos países relevantes foram unilaterais. Em parte, essa mudança decorria da contínua perda de valor da prata frente ao ouro nos anos anteriores a 1870. Esse fenômeno explica o fato de tantos países entrarem no padrão ouro em um período relativamente curto.

Como salientou Gallarotti: "Once conditions in the market for metals changed in the late 1860s and early 1870s in a way that significantly raised the bullion value of gold relative to that of silver (i.e., made it more profitable to hold gold as bullion and silver as money), nations moved to demonetize silver so as to keep gold in circulation. The rapidness of the transition was the result of the high level of trade and financial interdependence among nations, which served to link them together into a kind of monetary chain gang: transition in any one or several important nations meant that the others were compelled to follow along" (Gallarotti (1994, p. 142). Os países que aderissem ao padrão ouro por último sofreriam mais a pressão de especuladores sobre suas paridades fixas entre os dois metais. As reservas internacionais de seus bancos em ouro tenderiam a se exaurir pela excessiva entrada de prata desmonetizada por seus parceiros.

Durante o padrão ouro, o financiamento e a liquidação das transações internacionais (comerciais e de investimento) foram efetivados em grande parte através de instrumentos de crédito privado - como as letras de câmbio. O principal mercado desses títulos era Londres e a unidade de conta desses papéis era a libra esterlina. A City era o centro natural dessas operações internacionais e provia serviços financeiros para todo o mundo da forma mais eficiente e barata. Com o tempo, os títulos comerciais ingleses se tornaram tão líquidos e seguros que passaram a ser utilizados como ativos financeiros, chegando mesmo a serem demandados como instrumentos de reserva pelos bancos. Mesmo assim, marcos e francos eram também amplamente utilizados, inclusive rivalizando com a libra nos mercados do continente europeu.

A forte presença da libra, no entanto, não significa dizer que o ouro não tivesse um papel próprio e relevante como moeda reserva internacional. A maior parte das reservas dos bancos centrais dos 35 países mais relevantes em 1913 era composta por barras desse metal $(68,1 \%)$ e o restante dividido em partes quase iguais entre divisas estrangeiras e estoques de prata (Galarotti, 1995). Do total das reservas em divisas, a libra era a moeda mais importante, 
Ernani Teixeira Torres Filho

mas detida em montante semelhante ao conjunto dos valores denominados em francos e marcos.

O ouro era a última reserva do sistema, uma vez esgotadas as disponibilidades em moedas estrangeiras. Estas, por sua vez, tinham sua liquidez baseada na expectativa de sua conversibilidade em ouro. $\mathrm{O}$ uso do metal em transações internacionais, obviamente, tendia a aumentar nos momentos de crise financeira, que na prática foram eventos pouco comuns entre 1870 e 1914, envolvendo grandes centros financeiros do sistema, como Londres, Paris, Berlim e Nova Iorque.

Por fim, o papel dos bancos centrais nas transações internacionais era muito pequeno frente aos volumes transacionados pelo setor privado. $\mathrm{O}$ ambiente era muito desregulado deixando plena liberdade de ação para os atores privados. O manejo das autoridades monetárias, em geral, era feito através de instrumentos de mercado como as taxas de desconto e o preço do ouro.

Em suma, o padrão ouro não se constituiu a partir do poder monetário estrutural inglês. Nem se serviu de base para o exercício de poder monetário da Inglaterra sobre seus rivais. Sua existência decorreu da adesão não coercitiva dos demais países relevantes ao sistema que já era praticado na Inglaterra há décadas. Essas iniciativas foram voluntárias, em busca de integrar os diferentes sistemas monetários e financeiros nacionais nascentes ao centro financeiro principal, Londres, e à moeda dominante, a libra. Havia vantagens nessa integração em termos de escala e de custos de transação, públicos e privados. No caso dos Estados Unidos, o sistema financeiro inglês chegou a atuar de fato como banco central do sistema bancário americano. De acordo com De Cecco: "The largest source of weakness for London was, however, the 'American Account'. The United States used the London money market as its central bank" (De Cecco, 1974, p. 120).

Aos ingleses, a adesão das grandes nações ao padrão ouro proporcionou um aumento dos ganhos do seu sistema financeiro em termos da escala das operações que eram transacionadas em libras em Londres e da oferta de serviços financeiros especializados e de alto valor agregado. A centralidade do mercado inglês permitia ao seu Tesouro e a seus bancos operarem com as taxas de juros mais baixas do sistema e atrair para Londres uma massa enorme de capitais de todo o mundo. A autonomia política inglesa no sistema era, no entanto, relativa. O ouro servia como um forte limite ao uso político da vantagem financeira inglesa.

Ao mesmo tempo, a centralidade inglesa sobre o sistema era um bem que precisava ser preservado pelos demais países por interesse próprio, sob a ameaça de serem também impactados por uma crise financeira de proporções sistêmicas. Esse foi o motivo que fez com que franceses, alemães e russos corressem para ajudar o Banco da Inglaterra através de empréstimos em ouro para sustentar a paridade da libra, nos raros momentos em que a moeda inglesa esteve sob forte pressão dos mercados. 
Poder Monetário Estrutural: do padrão ouro ao dólar flexível

Os ingleses, ao longo da vigência do padrão ouro (1870-1914), detiveram o papel de administradores de um sistema globalmente integrado e os emissores da moeda básica de um "clube de ouro". Segundo Galarotti; "The gold standard partly compelled because international trade was financed disproportionately in sterling, nations desired access to the London capital market, and nations drew lessons from the British experience about the relationship between monetary standards and economic development (i.e., overlearning from history). But even here, the outcomes were somewhat different from the treatment in the literature on hegemonic regimes: the British did not purposively contribute to or orchestrate the structural compellence, and the process of socialization was a result of inferences drawn in foreign nations rather than the direct inculcation of norms or injunctions on the part of hegemonic agents" (Galarotti, 1995, p. 224).

\section{O poder monetário estrutural americano}

O processo de constituição do dólar como moeda central da economia internacional guardou grandes diferenças frente à montagem do padrão ouro-libra, que o antecedeu. A transição entre os dois sistemas não foi uma simples "mudança de guarda" entre moedas e países gestores do sistema monetário internacional. Pelo contrário, os americanos olharam a $2^{\mathrm{a}}$ Guerra Mundial como uma oportunidade não só para consagrarem sua moeda como peça central de um novo sistema que desejavam impor, mas também para desmontar seu único competidor próximo, a Inglaterra.

Essa estratégia foi distinta daquela que os EUA seguiram ao final da $1^{\text {a }}$ Grande Guerra. Naquela oportunidade, se preocuparam apenas em garantir, para seus bancos e para sua moeda, uma presença forte e ativa no mercado internacional. Wall Street passaria a ser um competidor relevante da City e o dólar seria uma entre as moedas relevantes no sistema monetário internacional. Isto foi possível graças aos esforços conjuntos dos bancos americanos e do então recém-criado Federal Reserve, o banco central americano, para desenvolver um mercado de câmbio amplo e profundo em Nova Iorque, baseado no dólar. Os EUA foram a única praça de câmbio que se manteve aberta durante toda a $1^{\text {a }}$ Guerra (Miaguti, 2016).

A entrada dos Estados Unidos no "clube do ouro", como ator relevante nos mercados e na governança internacionais, gerou, no entanto, desequilíbrios estruturais que impediram que o sistema monetário internacional conseguisse, de forma estável, retornar ao status quo pré-1914. Isso se deveu à escala que os financiamentos dos ingleses junto ao sistema financeiro americano em dólares adquiriram durante e nos anos que se seguiram ao conflito e à concorrência exercida por Nova Iorque como centro financeiro internacional de porte.

Ao final da $1^{\text {a }}$ Guerra, os créditos acumulados pelos EUA contra os Aliados atingiram US\$ 12 bilhões, sendo US\$ 5 bilhões devidos pelos ingleses. A posição credora americana foi, ao longo dos anos 1920, reforçada por elevados superávits externos, que totalizaram US\$ 11 bilhões. Como resultado, os Estados Unidos em 1923 detinham dois terços de todas as reservas 
em ouro dos bancos centrais. Esse volume era muito maior do que o que era necessário para o banco central americano garantir a liquidez internacional do dólar (Ahamed, 2009).

Apesar dessa posição financeira pujante, os EUA atuaram fortemente para que a Inglaterra retornasse ao padrão ouro o mais rapidamente possível. Operaram abertamente para que o papel de coordenação do sistema fosse mantido com o BoE e para que a moeda internacional dominante continuasse a ser a libra. Segundo Ahmed, o presidente de fato do Federal Reserve à época, Benjamim Strong "remained convinced that given the importance of the pound to world trade, a global return to the gold standard would only be possible if Britain took the lead: "The great problem is sterling, the others will come along easily if sterling could be dealt with," he kept telling his colleagues" (Ahamed, 2009, p. 76).

Strong e os banqueiros do J.P Morgan - principal banco internacional americano teriam inclusive oferecido em 1924 ao presidente do BoE, Norman Montagu, um empréstimo de US\$ 200 milhões proveniente do New York Fed, mais uma promessa de US\$ 300 milhões que viriam do J. P. Morgan. O retorno da libra ao regime de câmbio fixo do padrão ouro mostrou-se, no entanto, um fardo demasiadamente pesado para a Inglaterra e foi novamente suspenso em 1931.

$\mathrm{Na} 2^{\mathrm{a}}$ Guerra, o financiamento americano aos britânicos foi realizado em bases distintas do conflito de 1914. Até 1941, os britânicos usaram suas reservas em ouro e em divisas para liquidar seus pagamentos com os EUA. Esse modelo chegou à exaustão em junho daquele ano. Naquela data, o BoE dispunha de apenas US\$ 50 milhões em ouro e o Tesouro inglês menos de US\$ 100 milhões. Eram valores muito baixos, inferiores ao mínimo necessário para sustentar a libra e as necessidades dos países do Império (Woods, 1990).

Entre 1941 e 1945, foi criado um mecanismo de financiamento especial, o lend-lease, por meio do qual os americanos realizaram, como parte do esforço de guerra, doações a seus aliados, inclusive à Inglaterra. Apesar de não envolver a geração de uma dívida bilateral a ser negociada após o final do conflito, como em 1914, os EUA exigiram, em troca, compensações políticas. O compromisso mais importante dos ingleses era a eliminação, ao final o conflito, das preferências imperiais e do bloco da libra, criado em 1931. Esse princípio foi consagrado no Artigo VII do Anglo-American Mutual Aid Agreement, de fevereiro de 1942, em que se lia:

In the final determination of the benefits to be provided to the United States of America by the Government of the United Kingdom in return for aid furnished under the Act of Congress of March 11, 1941, the terms and conditions thereof shall be such as not to burden commerce between the two countries, but to promote mutually advantageous economic relations between them and the betterment of world-wide economic relations. To that end, they shall include provision for agreed action by the United States of America and the United Kingdom, open to participation by all other countries of like mind, directed to the expansion, by appropriate international and domestic measures, of production, employment, and the exchange and consumption of goods, which are the material foundations of the liberty and welfare of all peoples; to the elimination of all forms of 
Poder Monetário Estrutural: do padrão ouro ao dólar flexível

discriminatory treatment in international commerce, and to the reduction of tariffs and other trade barriers (...) (Grifo nosso).

A questão da ruptura definitiva do bloco da libra havia sido introduzida pelos americanos nas negociações bilaterais no ano anterior, durante a elaboração da Carta do Atlântico. O tema era controverso já que ambos os lados tinham clareza que a sujeição da Inglaterra a um multilateralismo imediato seria incompatível com as condições de financiamento da balança de pagamentos inglesa ao fim do conflito.

Para reduzir o poder de resistência dos ingleses, o governo dos EUA contingenciou seus financiamentos à Inglaterra ao longo da guerra de modo a evitar que o aliado acumulasse um saldo em dólares superior a US\$ 1 bilhão. Sempre que esse valor era superado, os recursos para importações de natureza civil eram reduzidos. Esse tipo de controle não foi, no entanto, estendido a outros países. A União Soviética, por exemplo, foi autorizada a manter saldos em dólares muito superiores aos dos ingleses (Woods, 1990).

A subordinação da libra ao poder monetário americano voltaria ainda a ser nesse período tratada como tema central de dois outros mecanismos de cooperação entre os dois países. No acordo de Acordo de Bretton Woods (BW), firmado em 1944, apenas o dólar foi mencionado como moeda alternativa ao ouro como reserva do novo sistema. Desse ponto de vista, a libra em nada se diferenciava das moedas dos demais países. No ano seguinte, com o fim do conflito o lend-lease, foi imediatamente suspenso e os ingleses voltaram a acumular dívidas em dólares. Nessa oportunidade, os americanos voltaram à carga e exigiram o retorno em prazo curto da plena conversibilidade da libra. Em troca, se comprometeram com um empréstimo de US\$ 3,75 bilhões em dinheiro novo, valor pequeno para assegurar condições aos ingleses para estabilizar sua economia.

Como esperado, a tentativa de tornar a libra conversível em 1947 teve curta duração. Houve um forte ataque especulativo que obrigou à reimposição de controles cambiais em menos de um mês. Ingleses e americanos não tinham dúvidas que isso aconteceria. Entretanto, os americanos desejavam promover o mais rápido possível o desmantelamento do império britânico e, consequentemente, eliminar qualquer resquício do papel histórico da libra como moeda central no sistema monetário internacional. Do ponto de vista do governo da Inglaterra, era melhor, por motivos estritamente políticos, postergar a crise cambial por 12 meses do que ser obrigado a atravessá-la em 1946.

Conforme apontado por Mann: "The terms of US entry into the Second World War and the terms of the settlement of 1945-6 were both designed to weaken British post war power. Thus US goods imports now had equal access to the Empire; thus the crippling burden of dollar debt in 1945 was to be paid by the import of US goods; thus the US insistence on the convertibility of sterling. In 1946 a rush to convert sterling holdings into dollar depleted Britain's gold and dollar reserves and caused a crisis. Convertibility was suspended in 1947 after a demonstration, satisfactory to the American eyes of sterling's vulnerability. This was 
calculated to finish off Britain's remaining global rivalry to the United States" (Mann, 1988, p. 215).

Além de eliminar seu principal rival na partida, o poder monetário estrutural americano determinou as características do novo sistema dólar-fixo (Serrano, 2002). O sistema de Bretton Woods (BW) não foi uma simples atualização dos mecanismos existentes durante o padrão ouro (1871-1914), tendo agora o dólar na posição central. Diferentemente, a moeda americana teria um status único e garantido por legislação internacional. Além disso, a função do mercado financeiro privado no funcionamento do sistema seria diferente do que a City londrina tinha desempenhado até o início da $1^{\text {a }}$ Guerra.

A concepção que deu base a Bretton Woods respondeu a uma visão própria dos Estados Unidos sobre as características do novo sistema internacional e do papel da sua moeda. Entre os princípios que nortearam o acordo, dois foram destacados pelo Secretário do Tesouro americano da época, Henry Morgenthau. O primeiro deles era a intenção de retirar "the usurious money lenders from the temple of international finance (and) to move the financial center of the world from London and Wall Street to the United States Treasury and to create a new concept between the nations of international finance" (Steil, 2013, p. 125).

Em BW, os sistemas financeiros nacionais seriam internacionalmente desintegrados e sujeitos ao ordenamento das autoridades locais. As contas de capitais seriam inconversíveis. Os bancos privados americanos estabelecidos em Nova Iorque - grande praça financeira internacional - teriam sua atuação internacional limitada às operações de crédito comercial, não se aventurando no mundo das altas finanças como seus antecessores ingleses. Londres continuaria a existir, mas limitada às finanças do antigo império e com uma base precária: sua moeda nacional - a libra - conviveria por muito tempo com problemas de conversibilidade. Os ajustes de balanço de pagamentos, que viessem a requerer assistência americana, seriam operados bilateralmente com os EUA ou através de organismos multilaterais, controlados pelos Estados Unidos. Finança internacional passaria a ser um jogo predominantemente interestatal.

O segundo princípio era o papel absoluto que o dólar teria no novo sistema monetário internacional. Isso significava submeter os demais países Aliados e, em particular, o Império Inglês, a cotar, pagar e se financiar externamente na moeda americana. Para tanto, seria melhor que não existissem rivais, que à semelhança do que havia acontecido nas décadas anteriores, pudessem criar obstáculos políticos ou servir de base a especulações contra o regime de taxas de câmbio fixo que estava sendo implantado. Os EUA já não se satisfariam, por motivos de segurança - e não apenas pelos interesses privados das empresas e bancos americanos - em ver o dólar ser apenas mais uma entre as moedas relevantes. O objetivo era impô-la, de partida e de forma permanente, como dominante.

O poder monetário estrutural americano voltaria a se manifestar novamente na passagem do sistema do dólar fixo para o dólar flexível em 1971 (Serrano, 2002). Nesta oportunidade, os EUA unilateralmente suspenderam a conversão de sua moeda em ouro a uma paridade fixa, descumprindo os termos do Acordo de Bretton Woods. A frase que talvez melhor 
Poder Monetário Estrutural: do padrão ouro ao dólar flexível

ilustre o espírito que presidiu essa decisão foi proferida à época pelo Secretário do Tesouro dos Estados Unidos, John Connally, perante uma plateia atônita de outros ministros da Fazenda: "The dollar is our currency, but it's your problem" (Whitley, 2013, p. 21).

Essa medida, que deu origem à ruptura do sistema de taxas de câmbio fixo do pósguerra, gerou espanto generalizado e foi visto por alguns autores como uma resposta precipitada a uma imposição dos mercados financeiros. Michael Moffitt, por exemplo, entende que "a causa imediata da morte do sistema de Bretton Woods foi a maciça especulação contra o dólar" (Moffitt, 1984, p. 75). Essa também era a opinião de burocratas americanos, como Paul Volcker para quem abandonar a conversibilidade do dólar em ouro era uma resposta ao pânico de mercado (Volcker; Gyohten, 1992).

De fato, o aumento da liquidez do dólar e a falta de confiança dos mercados na capacidade de o governo americano sustentar a conversibilidade da sua moeda em ouro tinham gerado fortes ondas especulativas nos anos anteriores. Entretanto, a ruptura do sistema monetário não foi uma decisão precipitada. Em todos os momentos, nesse período, a instabilidade dos mercados de câmbio conseguiu ser controlada. Além disso, não há sinais de que Washington já tivesse esgotado suas opções para lidar com esse problema. Entre as alternativas que lhes restavam estavam: a desvalorização do dólar, o aumento das taxas de juros nos EUA e a realização de intervenções no mercado de ouro.

Entretanto, todas essas medidas tinham consequências indesejáveis sobre as políticas interna e externa, o que fez com que os presidentes americanos não estivessem interessados em arcar com esse preço. Paul Volcker, que era Subsecretário Internacional do Tesouro nesse período, relembrou em suas memórias que: "Presidents - certainly Johnson and Nixon - did not want to hear that their options were limited by the weakness of the dollar. Consider the issue of maintaining our troops in Germany and Japan. It would be a gross simplification to boil all that down to a calculation of how many U.S. divisions abroad were worth how much loss of gold" (Volcker; Gyoten, 1992, p. 61).

Além disso, a dependência de uma ação concertada de forma mais permanente com outros países para apoiar a relevância da moeda americana no mercado internacional tinha um custo elevado para os Estados Unidos. Como apontou Strange, seria, na prática, como decretar o fim da hegemonia absoluta do dólar e deixar os EUA expostos a pressões dos países que cooperassem na sustentação da sua moeda. Os franceses chegaram a trilhar esse caminho (Strange, 1976). Nos anos 1960, aceleraram a conversão das suas reservas de dólares para ouro, inclusive transportando os lingotes de Nova Iorque para Paris, o que não era a prática normal. Ademais, criticaram abertamente o que chamaram de "privilégio exorbitante" americano, que se traduziria nas vantagens que o sistema de BW daria aos EUA em termos de manutenção de níveis de vida elevados para sua população e no subsídio a suas multinacionais à custa de seus parceiros externos.

A decisão americana de 1971 foi o passo final de uma estratégia que foi primeiramente enunciada em 1966. (KIRSHNER, 1995). No ano seguinte, Kindleberger argumentava que o 
padrão dólar flexível seria a melhor opção a ser adotada uma vez que: "a return to gold as advocated by the French, the adoption of a new international currency proposed by Triffin, or of a new international asset to supplement gold and dollars, under consideration by the Group of Ten, would each be contrived, artificial, and less efficient than the dollar standard, with liquidity supported by an international capital market centered on New York and its Eurodollar and Eurodollar-bond extensions" (Kindleberger, 1967, p. 1).

Essa ideia ganhou corpo posteriormente no relatório de 1969 do chamado "Volcker Group", que incluía membros das diferentes agências econômicas do governo americano, além do Conselho de Segurança Nacional. Esse documento descartava a opção de desvalorização unilateral do dólar, devido à previsão de que outros países seguiriam o movimento e desvalorizariam suas próprias moedas na mesma proporção, Recomendava como alternativa a suspensão da conversibilidade (Aguiar, 1995, p. 62-63) Essa decisão deveria, por sua vez, ser tomada de forma que parecesse uma resposta involuntária de Washington a uma situação de crise, "[i]n the interests of facilitating international harmony, the appearance of US hegemony should not be sought" (U.S. Department of the Treasury, 1969, p. 6).

A política financeira ao final da década (benign neglect) mostra que, na prática, os EUA haviam, desde o final dos anos 1960, adotado uma postura passiva frente a seus déficits externos. Era como se o governo estivesse esperando o melhor momento para eliminar, de uma vez por todas, a principal restrição à ação política americana: a conversibilidade do dólar em ouro.

A ruptura de BW e o dólar flexível foram vistos como sinais de uma perda de hegemonia por parte dos Estados Unidos. Essa situação seria evidenciada ainda pelos elevados déficits externos americanos, em um mundo de baixo crescimento e sujeito a um grande número de crises localizadas. Entretanto, como esclarece Strange: "to run a persistent deficit for a quarter of a century with impunity indicates not American weakness, but rather American Power in the system. To decide one August morning that dollars can no longer be converted into gold was a progression from exorbitant privilege to super-exorbitant privilege; the U.S. government was exercising the unconstrained right to print money that others could not (save at unacceptable cost) refuse to accept in payment" (Strange, 1987, p. 569).

A decisão americana levou o sistema monetário e financeiro internacional a se reestruturar em bases novas. As taxas de câmbio tornaram-se flexíveis e os fluxos de capitais foram inteiramente liberados. A instabilidade nas paridades passou a ser gerenciada por meio de contratos privados de seguro, os derivativos, e não mais pela garantia dos bancos centrais. A intermediação bancária deu lugar à securitização de ativos. Os volumes de ativos financeiros e de alavancagem atingiram níveis impensáveis até então (Torres, 2014).

Entretanto, essas transformações não foram antecipadas pelos atores que efetivaram a ruptura do sistema de BW. A certeza quanto ao rumo para o reordenamento financeiro internacional não era condição prévia para que os EUA adotassem as medidas necessárias à retomada de sua hegemonia monetária. O propósito era simplesmente aumentar o raio de 
Poder Monetário Estrutural: do padrão ouro ao dólar flexível

manobra da política americana, a partir do seu poder monetário estrutural, que estava intacto. Era o início de um processo que foi posteriormente chamado por Tavares de "A Retomada da Hegemonia Americana" (Tavares, 1985).

\section{Conclusão}

A Revolução Financeira Inglesa, dos séculos XVII e XVIII, produziu uma das principais transformações do sistema capitalista. Em um intervalo curto de tempo, três instituições foram integradas em um único mecanismo: a dívida pública, agora modernizada para atender condições de valorização exigidas pelo mercado de capitais; o banco central, recém-criado para dar conta da liquidez da dívida pública, dos bancos e dos mercados; e os mercados secundários de ativos, mecanismo de liquidez, que potencializa a ação dos outros dois.

A motivação política original dessa inovação institucional foi ampliar a capacidade do governo da Inglaterra financiar - e consequentemente, ganhar - os recorrentes conflitos militares em que estava envolvida. As guerras necessitavam a mobilização de um volume muito elevado de recursos em um espaço de tempo curto. $\mathrm{O}$ simples aumento da taxação não conseguia atender a esses quesitos na dimensão e no prazo necessários. O uso de outros mecanismos de financiamento, como a redução do conteúdo metálico das moedas e os empréstimos compulsórios havia, ao longo dos séculos anteriores, gerado impactos negativos sobre a economia, os financiadores privados e o crédito público

O resultado da Revolução Financeira foi estrondoso. A Grã-Bretanha acumulou uma vantagem em termos de mobilização de recursos financeiros sobre seus oponentes que se manteve até a $1^{\text {a }}$ Guerra Mundial. O crédito inglês permitiu que a aquisição de armas e soldados pelos ingleses se desse através da emissão de títulos enquanto seus inimigos, pelo menos até Napoleão, precisavam recorrer ao ouro e à expropriação para atingir o mesmo objetivo.

O novo arranjo monetário-financeiro também conquistou para a Inglaterra uma posição central nas finanças internacionais. Londres passou a ser a principal praça financeira internacional, centralizando o financiamento do comércio global, do investimento externo e da dívida pública de outros países. Isso permitiu o surgimento de segmentos especializados que proviam ao resto do mundo serviços financeiros a preços e taxas de juros muito competitivos. A libra esterlina, por sua vez, passou a denominar a maior parte desses ativos e ser a moeda de liquidação preferida nas transações internacionais.

Os mecanismos institucionais desenvolvidos pelos ingleses foram sendo emulados por seus rivais, Dutch finance, banco central e mercados secundários de ativos. A partir de 1870, os principais sistemas monetário-financeiros das nações relevantes foram se integrando ao inglês, por meio da adoção do padrão ouro. Em nenhum dos casos essa decisão foi feita por força de coerção ou de qualquer outra forma de imposição por parte da Inglaterra. A aceitação do padrão ouro foi sempre unilateral e relacionada às vantagens esperadas em termos de taxas de juros e prazos. Adotar o ouro como lastro da moeda nacional era uma forma de o país 
adquirir uma condição de baixo risco de crédito, a exemplo do que acontece nos dias de hoje com a preocupação de países para obterem os melhores ratings das classificadoras de risco internacionais.

Não há evidência de que, no padrão ouro, a Inglaterra tenha exercido um papel hegemônico do ponto de vista monetário ou que a montagem desse primeiro sistema monetário internacional moderno tenha sido o resultado do exercício de seu poder estrutural. A centralidade da City e da libra esterlina atribuíram ao Banco da Inglaterra um papel dominante na governança do sistema e resultavam em vantagens para os ingleses em termos de taxas de juros e de custo de ajustamento. Do mesmo modo, quando o padrão ouro se tornou disfuncional para os ingleses, os britânicos também não conseguiram impor ao resto do mundo um novo padrão que, ao mesmo tempo, resguardasse a centralidade da libra e os interesses do país.

Esse cenário guarda pouca semelhança com a origem do sistema monetário baseado no dólar, implantado a partir de 1945. Esse episódio não foi uma simples "mudança de guarda" em que uma nova moeda - a americana - e um novo hegemon - os Estados Unidos - tomaram a liderança antes ocupada pela libra e pela Inglaterra. A montagem do primeiro sistema baseado no dólar, com taxas de câmbio fixas, foi o resultado de uma operação do Estado Nacional americano que se iniciou concomitantemente com sua entrada na $2^{\text {a }}$ Guerra.

O apoio financeiro ao esforço de guerra inglês foi concedido em troca do compromisso com a desmontagem do império britânico e consequentemente com a eliminação, de uma vez por todas, da libra com moeda potencialmente concorrente no sistema monetário internacional. Com a Inglaterra fora do páreo, o resto do mundo se submeteu às regras monetárias impostas pelos americanos, à exceção da União Soviética e de seus países satélites.

Novamente, o poder monetário estrutural americano se manifestou em 1971 quando o Acordo de Bretton Woods precisou ser desmontado junto com os mecanismos que permitiam taxas de câmbio fixas e a conversibilidade do dólar em ouro a uma dada paridade. A decisão foi imposta unilateralmente pelos Estados Unidos a seus parceiros e deu origem ao atual sistema monetário baseado em taxas flutuantes, o dólar flexível.

Esse episódio foi inicialmente visto como um sinal de enfraquecimento do poder americano no mundo. Desse ponto de vista, a decisão dos EUA de romper o padrão dólar fixo teria sido uma resposta inevitável e passiva frente às fortes pressões especulativas dos mercados e dos bancos centrais europeus sobre o Federal Reserve. Entretanto, documentos recentemente liberados pelo Tesouro dos Estados Unidos mostram que esta decisão já havia sido tomada em segredo em 1969 e que ficou à espera de uma oportunidade política para ser adotada.

As décadas seguintes mostraram que o poder hegemônico e estrutural americano estava longe de ter se esgotado. O fim da União Soviética foi um marco importante desse processo. Outro elemento importante, que evidencia a capacidade de condução que os EUA detêm no cenário internacional, foi a constituição de um sistema financeiro globalizado baseado em taxas 
Poder Monetário Estrutural: do padrão ouro ao dólar flexível

de câmbio flexíveis e em uma moeda fiat - o dólar americano. Esse sistema dólar flexível já perdura por mais de três décadas, apesar das inúmeras que suscitou.

A resposta americana à crise financeira de 2008 mostrou, a despeito das desconfianças iniciais, que o dólar continua a ser a moeda central do sistema internacional, sem rivais a sua altura. Desse ponto de vista, as ameaças externas ao poder monetário americano não parecem ser relevantes no futuro previsível. Nesse sentido, sua principal fonte de instabilidade se encontra no interior dos Estados Unidos, no aumento dos conflitos internos. Essa perspectiva já havia sido anunciada por Susan Strange há duas décadas. Segundo ela: "(T)he decline in American hegemonic power lies within the American political system rather than in the role of the United States in the international system. Stability in these regimes requires, above all, some consistency on the part of the leading participant. The United States is ill suited to sustaining this consistency in policy making” (Strange, 1987, p. 571-572).

\section{Referências bibliográficas}

AGUIAR, F. A economia política da ruptura de padrão monetário nos anos 70. Dissertação (Mestrado em Economia Política Internacional)-Instituto de Economia, Universidade Federal do Rio de Janeiro, 2017.

AHAMED, L. Lords of finance: the bankers who broke the world. New York: Penguin books, 2009.

BAGEHOT, W. Lombard street: a description of the money market. 1973. Available at: http://oll.libertyfund.org/titles/bagehot-lombard-street-a-description-of-the-money-market.

CARLOS, A.; NEAL, L.; WANDSCHNEIDER, K. The origin of the national debt: the financing and refinancing of the War of Spanish Succession, Economic Historian's Conference 2005. Available at: http://www.helsinki.fi/iehc2006/papers1/Carlos.pdf.

CARLOS, A.; NEAL, L. Amsterdam and London as financial centers in the eighteenth century. Financial History Review, v. 18, n. 1, p. 21-46, 2011. Available at: http://eprints.1se.ac.uk/38799/.

CHEY, H. The concepts, consequences, and determinants of currency internationalization. GRIP. 2013. (Discussion Paper 13-03). Available at: http://www.grips.ac.jp/r-center/wpcontent/uploads/13-03.pdf.

COHEN, B. Organizing the world's money: the political economy of international monetary relations. New York: Basic Books, 1977.

COHEN, B. The future of sterling as an international currency. London: Macmillan, 1971.

CONTI, B.; PRATES, D.; PLIHON, D. O Sistema Monetário Internacional e seu caráter hierarquizado. In: CINTRA, M.; MARTINS, A. (Org.). As transformações no sistema monetário internacional. Brasília: Ipea, 2013. 
Ernani Teixeira Torres Filho

DE CECCO, M. Money and empire. The International Gold-Standard, 1890-1914. Oxford: Basil Blackwell, 1974.

EICHENGREEN, B. Privilégio exorbitante: a ascensão e a queda do dólar e o futuro do sistema monetário internacional. Rio de Janeiro: Elsevier, 2011.

FUNDO MONETÁRIO INTERNACIONAL - FMI. IMF Releases Data on the Currency Composition of Foreign Exchange Reserves Including Holdings in Renminbi. Washington, DC: Mar. 31, 2017. Available at: http://www.imf.org/en/News/Articles/2017/03/31/pr17108IMF-Releases-Data-on-the-Currency-Composition-of-Foreign-Exchange-Reserves.

GALLAROTTI, G. The anatomy of an international monetary regime: the classical gold standard 1880-1914. Oxford University Press, 1995.

KINDLEBERGER, C. The politics of international money and world language. Princeton: International Finance Section, 1967. (Essays in International Finance, n. 61). Available at: https://www.princeton.edu/ ies/IES_Essays/E61.pdf.

KIRSHNER, J. Currency and coercion: the political economy of international monetary power. Princeton, N.J: Princeton University Press, 1995.

MANN, M. States, war and capital. Blackwell, 1988.

MARTIN, F. Money: the unauthorized biography. London: Vintage, 2014.

MIAGUTI, C. A ascensão do dólar e a crise do padrão ouro-libra (1913-1931). Dissertação (Mestrado em Economia Política Internacional)-Instituto de Economia, Universidade Federal do Rio de Janeiro, 2016. Disponível em: https://franklinserrano.files.wordpress.com/2017/03/carol-mia-versc3a3o-finaldissertac3a7c3a3o-2017.pdf.

MOFFITT, M. O dinheiro do mundo: de Bretton Woods à beira da insolvência. Rio de Janeiro: Paz e Terra, 1984.

ROSEVEARE, H. The financial revolution: 1660-1760. London: Longman, 1991.

PLESSIS, A. When Paris dreamed of competing with the city. In: CASSIS, Y.; BUSSIÈRE, E. (Ed.). London and Paris as International Financial Centres in the Twentieth Century. Oxford University Press, 2005.

SERRANO, F. Do ouro imóvel ao dólar flexível. Economia e Sociedade, Campinas, jul./dez. 2002.

STEIL, B. The battle of Bretton Woods: John Maynard Keynes, Harry Dexter White, and the making of a new world order. Princeton: Princeton University Press, 2013.

STRANGE, S. The persistent myth of lost hegemony. International Organization, v. 41, n. 4, p. 551-574, 1987. 
Poder Monetário Estrutural: do padrão ouro ao dólar flexível

STRANGE, S. International monetary relations. In: SCHONFIELD. A. (Ed.). International monetary relations of the western world (1959-71). Oxford University Press, 1976.

SWIFT Worldwide Currency Usage and Trends. 2015. Available at:

https://www.swift.com/node/19186.

TAVARES, M. C. A retomada da hegemonia norte-americana. Revista de Economia Política, v. 5, n. 2, abr./jun. 1985.

TORRES, E. A crise do sistema financeiro globalizado contemporâneo. Revista de Economia Política, v. 34, n. 3 (136), p. 433-450, jul./set. 2014.

U. S. DEPARTMENT OF TREASURY. Basic options in international monetary affairs. Jun., 23 1969. Available at: https://history.state.gov/historicaldocuments/frus1969-76v03/d131.

VOLCKER, P.; GYOHTEN, T. Changing fortunes: the world's money and the threat to American leadership. New York: Times Books, 1992.

WHITLEY, A. The origins and use of currency power. Adelphy Series, v. 53, 439, p. 17-44, 2013.

WOODS, R. A changing of the guard: Anglo-American relations, 1941-1946. University of North Carolina Press, 1990. 